\title{
OS MÉTODOS ATIVOS DE ENSINO APLICADOS PELO PROFESSOR EXEMPLAR DE JOSEPH LOWMAN COMO INSTRUMENTOS POTENCIALIZADORES NA APRENDIZAGEM DO ENSINO JURÍDICO
}

\author{
Carla Vanessa Prado Nascimento Santos ${ }^{1}$ \\ Guilherme Augusto Melo Batalha de Gois ${ }^{2}$
}

\begin{abstract}
Resumo: O presente artigo destina-se a analisar, primeiramente, o nascimento do ensino jurídico no Brasil, para então refletir sobre o método tradicional aplicado ao longo desses anos e sua real eficácia. Serão propostas técnicas pedagógicas de ensino, associadas ao modelo do professor exemplar de Joseph Lowman, a fim de que se maximize o aprendizado, e traga motivação e satisfação para o aluno e para o professor no ambiente universitário.
\end{abstract}

Palavras-chaves: ensino jurídico; método clássico; método ativo; professor; aluno.

\section{THE ACTIVE TEACHING METHODS APPLIED BY JOSEPH LOWMAN'S EXEMPLARY TEACHER AS POTENTIAL INSTRUMENTS IN LEARNING JURIDICAL TEACHING}

\begin{abstract}
This article aims to analyze, first, the birth of legal education in Brazil, to reflect on the traditional method applied over the years and its real effectiveness. Teaching techniques will be proposed, coupled with Joseph Lowman's exemplary teacher model, in order to maximize learning, and bring motivation and satisfaction to the student and to the teacher in the university environment.
\end{abstract}

Keywords: legal teaching; classical method; active method; teacher; student.

\footnotetext{
${ }^{1}$ Mestranda em Constitucionalização do Direito pela Universidade Federal de Sergipe. Pós-graduada em Direito Constitucional pela Universidade Cândido Mendes. Advogada. Domiciliada na Av. Beira Mar, $n^{\circ}$ 3538, Jardins, CEP 49.025-040, Aracaju/SE. E-mail: carlavansessa_pns @ hotmail.com.

${ }^{2}$ Mestrando em Constitucionalização do Direito pela Universidade Federal de Sergipe. Pós-graduado em Direito Processual Civil pela Escola Judicial do Estado de Sergipe. Pós-graduado em Direito Púbico pela Universidade Tiradentes. Advogado. Domiciliado na Rua Doutor José Roberto Ribeiro, ${ }^{\circ} 70$, Grageru, CEP 49.027-090, Aracaju/SE. E-mail: guilhermebatalha@live.com.
} 


\section{INTRODUÇÃO}

O presente artigo se propõe a analisar criticamente a adoção exclusiva do método tradicional no ensino superior do Brasil, em especial no jurídico, a partir de uma compreensão do surgimento histórico das universidades brasileiras e o método nelas utilizado desde esse momento.

Em seguida, passar-se-á para análise do método tradicional, que tem como forte característica as aulas expositivas, onde há o protagonismo do professor em detrimento da passividade do aluno e, consequente, a aprendizagem é comprometida em razão desse papel secundário do discente. Também será analisada outra característica marcante do modelo tradicional do ensino jurídico, a ênfase no verbalismo, onde docente de forma exclusiva transmite verbalmente as informações, implicando em um atrofiamento do pensamento crítico dos alunos.

Também, buscar-se-á demonstrar que a experiência do professor ou seu vasto conhecimento jurídico não é garantia de sucesso na aprendizagem dos alunos, sendo necessária a adoção de técnicas pedagógicas para sejam alcançados resultados satisfatórios.

Identificar-se-á quais seriam esses métodos pedagógicos que são capazes de proporcionar, ao professor e ao aluno, motivação e satisfação em estarem na sala de aula. Para isso serão utilizadas reflexões acerca das contribuições de Piaget para a educação, além de sugerir a adoção do ensino exemplar proposto por Joseph Lowman. Por fim, será abordado o método ativo, como mecanismo capaz de garantir resultados eficientes na aprendizagem, trazendo a figura do aluno como protagonista dessa arena dramática, que é a sala de aula.

\section{BREVE RELATO DO SURGIMENTO DO ENSINO SUPERIOR NO BRASIL}

O ensino superior no Brasil, ao contrário do que ocorreu nas Américas Espanhola e Inglesa, só surgiu trezentos anos após o descobrimento do nosso país. Apenas em 1808, após o bloqueio continental da Europa, promovido por Napoleão Bonaparte, que barrou o acesso às universidades européias, como a de Coimbra, (uma das favoritas 


\section{OS MÉTODOS ATIVOS DE ENSINO APLICADOS PELO PROFESSOR EXEMPLAR DE JOSEPH LOWMAN COMO INSTRUMENTOS POTENCIALIZADORES NA APRENDIZAGEM \\ DO ENSINO JURÍDICO}

dos fidalgos brasileiros que possuíam o privilegio de adentrar no ensino superior), criouse no Brasil os cursos jurídicos. No ano de 1827, no dia 11 de agosto, nasceram os cursos jurídicos em Olinda, depois transferido para Recife, e em São Paulo, no convento dos franciscanos, no Largo São Francisco (SOUZA, 2001, p. 10).

O corpo docente dos cursos de direitos da época era trazido da Europa Ocidental, sendo importado junto com ele o modo de pensar e a técnica de ensino. As aulas eram expositivas, com abuso do verbalismo, tendo este modelo se perpetuado ao longo de gerações. Sobre as primeiras instituições de ensino jurídico no Brasil comenta Patrícia da Silva Pires:

Note-se que, desde as primeiras instituições de ensino jurídico de nível superior que foram criadas no Brasil, há o predomínio de uma metodologia baseada na aulaconferência, sem se ater à realidade sóciocultural do país, muito menos a uma aprendizagem crítica do Direito enquanto ferramenta de transformação social (PIRES, 2006, p. 241).

Percebe-se que está enraizado em nossa cultura o método clássico de ensino. Nessa metodologia, prima-se pelas aulas expositivas, sem se preocupar com técnicas metodológicas de ensino que possam potencializar a aprendizagem dos alunos. A seguir analisaremos algumas características marcantes do método tradicional de ensino, que ainda é encontrado, corriqueiramente, nas universidades do país.

\section{MÉTODO TRADICIONAL DE ENSINO JURÍDICO}

Um dos métodos tradicionais de ensino jurídico é o expositivo. É uma tradição brasileira em virtude da importação do modelo da Europa Ocidental do século XVII. Como já fora explicitado, as primeiras universidades brasileiras remontam a época do Brasil Império (fundação da Universidade de Olinda e de São Paulo, em 1827), que tiveram seus métodos de ensino pautados, especialmente, no método empregado na Universidade de Coimbra em Portugal.

De acordo com Antonio Carlos Gil, em sua obra Metodologia de Ensino Superior, a aula expositiva é utilizada nas faculdades de Direitos praticamente de forma 
exclusiva e "consiste numa preleção verbal utilizada pelos professores com o objetivo de transmitir informações a seus alunos (GIL, 2009, p.68).

Godoy aponta para as seguintes limitações da aula expositiva:

Pouca participação do aluno em função da comunicação unilateral característica desta técnica de ensino. Considera a classe como um grupo uniforme; não levando em conta o fato de que os alunos possuem estilos de aprendizagem diferenciados. Não considera o fato de que muitos ou alguns alunos não possuem os conhecimentos prévios necessários. Não favorece o desenvolvimento das habilidades intelectuais mais complexas (aplicação, análise, síntese e julgamento) que levem o aluno a pensar sobre o que aprendeu. Não possibilita que o professor realize a função de avaliação acompanhando o aprendizado (ou não) do aluno. Às vezes cria o hábito de os alunos estudarem através de suas anotações não recorrendo à bibliografia indicada pelo professor (GODOY, 1997, p. 78-79).

O professor Paulo Freire chama esse método tradicional de "educação bancária" e critica as aulas expositivas no ensino do direito:

Narração de conteúdos que, por isso mesmo, tendem a petrificar-se ou a fazer-se algo quase morto, sejam valores ou dimensões concretas da realidade. Narração ou dissertação que implica um sujeito - o narrador - e objetos pacientes, ouvintes - os educandos. Há uma quase enfermidade da narração. A tônica da educação é preponderantemente esta - narrar, sempre narrar [...] Por isto mesmo é que uma das características desta educação dissertadora é a "sonoridade"da palavra e não sua força trnsformadora. [...] a narração, de que o educador é o sujeito, conduz os educandos à memorização mecânica do conteúdo narrado. Mais ainda, a narração os transforma em "vasilhas, em recipientes a serem enchidos pelo educado. Quanto mais vá "enchendo" os recipientes com seus "depósitos", tanto melhor educador será. Quanto mais se deixem docilmente "encher, tanto melhores educandos serão.Desta maneira, a educação se torna um ato de depositar, em que os educando são os depositários e o educador o depostiante. Em Lugar de comunicar-se, o educador faz "comunicados"e depósitos que os educandos, meras incidências, recebem pacientemente, memorizam e repetem. Eis aí a concepção "bancária" da educação, em que a única margem de ação que se oferece aos educandos é a de receber os depósitos, guardá-los e arquivá-los (FREIRE, 2005, p. 65-66).

Esse método clássico de ensino jurídico, onde o docente de forma exclusiva transmite verbalmente as informações, implica em um atrofiamento do pensamento crítico dos alunos. A conseqüência é a ausência de reflexões dos problemas jurídicos e uma homogeneidade de um só pensamento. Essa inexistência de crítica se dá em virtude 


\section{OS MÉTODOS ATIVOS DE ENSINO APLICADOS PELO PROFESSOR EXEMPLAR DE JOSEPH LOWMAN COMO INSTRUMENTOS POTENCIALIZADORES NA APRENDIZAGEM DO ENSINO JURÍDICO}

da posição passiva imposta ao discente que são induzidos a receber os ensinamentos jurídicos de acordo com as diretrizes que foram passadas pelo docente.

Essa forte característica do método expositivo resulta no protagonismo do professor em detrimento da passividade do aluno que "condenados ao silêncio, são compelidos a um comportamento passivo e não-questionador, num desestímulo a qualquer reflexão crítica" (MELO FILHO, p. 56). Por conseguinte, a aprendizagem é comprometida em razão desse papel secundário do discente, como bem explica Antonio Gil:

A adoção desse modelo torna problemática a aprendizagem. O professor preocupa-se em expor a matéria e negligencia a importância do interesse e da atenção do aluno. Seu discurso inclui termos que nem sempre existem na experiência dos alunos. Tantas são as idéias apresentadas, que boa parte delas não é retida pelos alunos. Alguns professores falam tão rápido que muitas das idéias apresentadas não são percebidas pelos alunos. Outros falam tão baixo de forma tão monótona que não conseguem manter a atenção dos alunos (2009, p. 69).

Outra característica marcante do modelo tradicional do ensino jurídico é a ênfase no verbalismo. Até os dias atuais é comum o uso por parte dos juristas de vocabulário robusto, farto em linguagem técnico- jurídica, que acaba excluindo grande parcela da sociedade. Nas faculdades de direito, muitas das vezes, o próprio aluno tornase vítima.

Esse verbalismo operante excessivamente nos cursos de Direito é resultado de uma técnica de ensino onde o professor, de maneira unilateral, transmite o conteúdo de forma acrítica. Não há um cenário para reflexão, restando apenas ao aluno decorar a matéria. O docente transmite o conhecimento, de forma repetida, expondo seus conhecimentos doutrinários e vasto jus glossário implicando é uma dissociação entre o conhecimento difundido e a realidade.

Para piorar a situação, esse "profissional”, na maioria das vezes, não se dá conta do ciclo vicioso do qual passou a fazer parte e continua repetindo os mesmos comportamentos. Quando tem a oportunidade de "transmitir" seus conhecimentos em uma sala de aula, agora como "professor de Direito", o faz sob o manto de uma falsa epistemologia construtiva, esboçada em seu plano de ensino nos objetivos da disciplina, mas totalmente dissociada da realidade e distante do diálogo, essencial nessa etapa que deveria primar pela efetiva construção do conhecimento (PIRES,2006, p. 250) 
Diante do exposto, cai por terra essa concepção de que o bom professor é aquele que usa uma retórica pautada em linguagens técnicas jurídicas sem atentar para recepção e boa compreensão do conteúdo por parte dos alunos.

Ademais, esse ensino fadigante por meio de monólogos enraizado na tradição das faculdades de Direito brasileiras, onde impera o discurso dogmático e formalístico, já era observado por Tobias Barreto que afirmava serem as faculdades verdadeiros laboratórios, oficinas da ciência e defendia a necessidade de se estimular o pensar autônomo.

No entendimento de Antonio Carlos Gil (2005), o modelo clássico traz consigo algumas vantagens, como exemplos, o fato de poder ser dada a matéria por qualquer profissional que detenha o domínio do tema, mesmo que não possua técnicas pedagógicas suficientes e por ser mais econômico que outros métodos.

A experiência do professor ou seu vasto conhecimento jurídico não é garantia de sucesso na complexa missão que é a docência. Álvaro Melo Filho traz as consequências de um ensino desinteressado técnicas pedagógicas:

Outrossim, é de irrecusável significado que a circunstância do advogado, do magistrado, do promotor e do procurador ser um profissional competente e de sucesso não assegura ipso facto habilitação e qualidade para docência jurídica. Como resultado, suas ações didáticas e instrumentais metodológicos, não raro, tornam-se "rotinas ineficazes", autoritárias, dogmatizadas, com os loquazes professores de Direito ensinando o certo e o errado ou transformando o quadrado em círculo, diante de alunos apáticos e silentes, cingidos à monocultura jurídica e "castrados" em qualquer reflexão crítica ou criativa, onde o professor é único modelo e o "livro adotado", a referencia maior. Exsurge aqui, com visibilidade, o teatro do ensino jurídico, tendo como enredo um direito pretensamente imutável e, onde os atores principais são, de um lado, os professores, com impotência verbal, fingindo que ensinam, e, do outro, os alunos, com subserviência metodológica, fazendo o jogo cênico de que aprendem. Em resumo, docentes e discentes são cúmplices de uma "farsa bem encenada" na tensão entre totalidade e particularidade, entre passado e futuro, entre memória e desejo, entre estrutura e processos (1977, p. 42).

É importante pontuar que os problemas atinentes ao modelo tradicional de ensino são minimizados ou, até mesmo deixam de existir, quando o professor abre para a possibilidade de interação com os alunos, possibilitando-os a refletir sobre o assunto. Ao 
utilizar de outras técnicas ou métodos de ensino, os docentes estimulam a reflexão dos seus alunos, abrem margem para um pensar autônomo e proporcionam uma maior eficiência no processo de aprendizagem.

\section{O MÉTODO ATIVO APLICADO PELOS PROFESSORES EXEMPLARES DE JOSEPH LOWMAN COMO FORMA DE GARANTIR UMA APRENDIZAGEM EFICAZ}

O processo de formação pedagógica atinge quase todos os docentes do ensino fundamental e médio nos dias de hoje. Esse estudo abarca matérias como psicologia da educação, didática, prática de ensino, dentre outras que contribuem para habitar os professores da melhor forma. Porém esse aparato não faz parte da realidade dos docentes de ensino superior. O enfoque na contratação desses profissionais é o domínio dos conhecimentos atinentes a matéria que irá ministrar. No mesmo sentido, entendendo pela necessidade de capacitação didática- pedagógica, explica Thais Colaço:

Com exceção dos professores universitários de pedagogia e licenciaturas, os demais, professores profissionais e os profissionais professores, independentemente da sua área de atuação e do seu regime de trabalho, na sua minoria, não são capacitados didáticopedagogicamente. ... Isso não significa que apenas o conhecimento técnico da didática, ou seja, a capacitação pedagógica, seja suficiente. O conteúdo da matéria é indispensável para o bom desempenho docente. Aliás, a junção entre a didática (técnica de ensino) com o conhecimento teórico e ou prático da disciplina é o ideal para se alcançar um ensino do Direito de qualidade. (2006, p. 20).

A Lei n. ${ }^{0}$ 9.394/96, que trata das diretrizes e bases da educação nacional, traz em seu corpo quais são os requisitos básicos que precisam ser atendidos pelo professor universitário, dentre as exigências, encontram-se a titulação de mestre ou doutor. $\mathrm{O}$ professor Antônio Carlos Gil atenta para os requisitos técnicos que os professores de ensino superior precisam atender, em outras palavras, as habilidades e conhecimentos pedagógicos essenciais na prática da docência universitária: “a) estrutura e funcionamento do ensino superior, b) planejamento de ensino, c) psicologia da aprendizagem, d) método de ensino, e) técnicas de avaliação.”(2009, p. 31). 
Como já fora dito anteriormente, o conhecimento pleno do assunto por parte do professor, desvencilhado de práticas pedagógicas, não garante a aprendizagem da matéria. Independente de previsão legal ou curricular, as práticas pedagógicas devem ser aceitas e utilizadas pelo professor, afinal este retém, em sala de aula, a intermediação do conhecimento.

Como uma das consequências da resistência às técnicas pedagógicas, a falta de profissionalização dos professores é um problema corriqueiro nesse universo do ensino jurídico que se instalou no Brasil.

Para agravar ainda mais a falta de conscientização da importância da profissionalização do magistério superior, não há homogeneidade nos profissionais de ensino do Direito no Brasil, pois hoje possuímos, nas universidades públicas e privadas, três grupos de professores. No primeiro grupo, existem profissionais que se dedicam apenas ao ensino superior. Dentre eles, encontramos aqueles que trabalham em mais de uma instituição e, consequentemente, têm pouco tempo para preparar aulas, se dedicar à pesquisa, à extensão, à formação e à capacitação. Outros, normalmente vinculados a uma única instituição pública, trabalham em regime de dedicação exclusiva. Teoricamente possuem mais tempo para a preparação de aulas, para pesquisa, para extensão, para formação, para capacitação; atuam na pós-graduação e ocupam cargos administrativos. Envolvem-se mais com a instituição, com os colegas e com os alunos. Mas o grande questionamento que se faz em relação a esses professores é de que como eles conseguem ensinar o que não vivenciam com a prática diária. O segundo grupo é formado por profissionais professores que atuam no mercado de trabalho nas diversas profissões do Direito como: advogados, procuradores, procuradores de justiça, juízes, delegados de polícia, fiscais, funcionários públicos, entre outros. Nesses casos, a docência representa uma atividade paralela, secundária em relação à atividade principal. Alguns se sentem apenas como profissionais do Direito e não profissionais da educação. Esses profissionais professores muitas vezes lecionam em mais de uma instituição de ensino e, devido às suas diversas atividades, dispõe de pouco tempo para se dedicar à preparação das aulas, à pesquisa, à formatação, à capacitação, à participação efetiva na instituição de ensino em que trabalham. No entanto, a sua experiência profissional entusiasma "os alunos com os outros desafios e as exigências do mundo mercadológico", apresentando "a realidade para a sala de aula". Algumas das suas aulas se resumem em comunicações de "enfadonhos relatos pessoais" e "os seus parâmetros profissionais são, portanto, os ganhos materiais". Desta forma, o fascínio pelos sinais exteriores de riqueza, associados ao sucesso e competência profissionais, se tornam mais nocivos do que a supervalorização da experiência pessoal. Observamos, nesses casos, que os alunos de Direito são seduzidos pelo poder que seus mestres detêm, imaginando um dia imitá-los, sendo detentores da autoridade e do poder. Podemos ainda fazer uma analogia com o pensamento de Paulo Freire, quando trata da relação entre opressores e oprimidos: Há, 


\section{OS MÉTODOS ATIVOS DE ENSINO APLICADOS PELO PROFESSOR EXEMPLAR DE JOSEPH LOWMAN COMO INSTRUMENTOS POTENCIALIZADORES NA APRENDIZAGEM \\ DO ENSINO JURÍDICO}

por outro lado, em certo momento da experiência existencial dos oprimidos, uma irresistível atração pelo opressor. Pelos seus padrões de vida. Participar destes padrões constitui uma incontida aspiração. $\mathrm{Na}$ sua alienação, querem, a todo custo, parecer com o opressor. Imitá-lo. Segui-lo. Isto se verifica, sobretudo, nos oprimidos de "classe média", cujo anseio é serem iguais ao "homem ilustre" da chamada classe "superior". Mas o grande problema que se encontra é generalizado, pois a complexidade em compor os quadros docentes do ensino superior se agrava quando se observa que grande parte desse contingente de intelectuais envolvidos no magistério não possui formação e capacitação didático pedagógica (COLAÇO,2006, p. 17-18).

A falta de conscientização da necessidade de profissionalização dos docentes, muitas vezes por eles mesmos, e a resistência a aplicação de métodos pedagógicos acarreta em prejuízos não só para o estudante, como também para os professores. A ausência de entusiasmo da turma reflete, muitas das vezes, no professor causando-lhe frustrações. Para combater esse prejuízo de ambos os sujeitos envolvidos no ensino, Joseph Lowman traz a figura do professor exemplar.

O professor Lowman em sua obra Dominado Técnicas de Ensino, aborda lições baseadas em um modelo bidimensional - criar tanto estímulo intelectual como empatia interpessoal junto aos alunos - para que se atinja um ensino exemplar pelos professores universitários.

Na primeira dimensão, A habilidade para criar estímulo intelectual possui dois componentes: a clareza da apresentação do professor e seu impacto emocional estimulante sobre os estudantes. Clareza está relacionada com o que se apresenta e impacto emocional estimulante resulta do modo como o material é apresentado (LOWMAN, 2004, p. 39) e não se confunde com o fato de apenas conhecer a matéria, embora seja necessário que o professor a domine.

Para um professor realizar um excelente trabalho, ele deve ser capaz de fazer muito mais do que simplesmente apresentar detalhes de uma matéria - e a maioria dos estudantes sabe disso. Eles gostam de receber uma perspectiva global e adoram comparar e confrontar os conceitos, além de aprender fatos isolados. Para serem capazes de apresentar a matéria com clareza, os professores devem abordar e organizar sua matéria como se eles também conhecessem pouco do assunto. Devem enfocar observações antigas, acontecimentos essenciais, pressupostoschave e percepções críticas de uma matéria e não se deixar distrair por qualificações e limitações que lhes interessam mais como acadêmicos. Isso lhes dá a capacidade de explicar um tópico complexo de forma 
simples. Professores exemplares compartilham essa facilidade de expor claramente (LOWMAN, 2004, p. 39).

Já o impacto emocional estimulante consiste na habilidade de prender a atenção do aluno, fazendo-o não se deixar interferir pelo meio externo. Para isso o professor pode utilizar de artifícios como se comportar de forma mais entusiasta, animada ou de maneira mais serena, calma. O importante é despertar a alta concentração do aluno fazendo uso dos mais diversos meios, afinal a sala de aula das universidades é, sobretudo, uma arena dramática.

Entretanto, entender a matéria não é a mesma coisa que estar intelectualmente estimulado por ela- por exemplo, estar tão completamente envolvido em uma apresentação a ponto de não ser distraído por pensamentos ou fantasias, ficar surpreso quando a aula termina ou ter compulsão para falar sobre o curso durante o dia com os outros. Para conseguir esse tipo de impacto sobre os estudantes, o professor deve fazer muito mais do que apresentar com clareza sua matéria. Em outras palavras, para a máxima eficiência nesta primeira dimensão, a clareza é necessária, mas não suficiente. Ela deve ser acompanhada pela virtuosidade em falar perante os grupos. Por que acreditar que essas coisas devem ser consideradas? As salas de aula das universidades são fundamentalmente arenas dramáticas nas quais o professor é o ponto focal, como o ator ou orador em um palco. Os estudantes estão sujeitos às mesmas influências - tanto em termos de satisfação quanto de distração- como qualquer público. Como os retratos de Epstein (1981) demonstram, dar aula é inegavelmente uma arte de interpretação. Para estarem seguros, os professores exemplares organizam suas aulas para promover um entendimento claro $\mathrm{e}$ complexo. Mas também usam suas vozes, seus gestos e movimentos para chamar e manter a atenção e para estimular a emoção dos estudantes. Como outros intérpretes, os professores devem, acima de tudo, transmitir um forte sentido de presença, de energia altamente concentrada. Alguns professores conseguem isso sendo extremamente entusiásticos, animados ou espirituosos, enquanto outros conseguem o mesmo efeito com um estilo mais calmo, mais sério e intenso, mas igualmente envolvente. A capacidade de estimular emoções fortes de forma positiva em estudantes separa o professor competente de outros excelentes professores universitários (LOWMAN, 2004, p. 40).

Dando seqüência, a segunda dimensão diz respeito ao relacionamento interpessoal. A sala de aula é um local onde se condensam vários tipos de emoções, ocorrendo diversos fenômenos psicológicos. Por exemplo, a motivação dos estudantes em trabalhar fora da aula será reduzida se eles sentirem que não são apreciados por seus professores ou que são controlados de modo coercitivo e autoritário (LOWMAN, 2004 p. 


\section{OS MÉTODOS ATIVOS DE ENSINO APLICADOS PELO PROFESSOR EXEMPLAR DE JOSEPH LOWMAN COMO INSTRUMENTOS POTENCIALIZADORES NA APRENDIZAGEM \\ DO ENSINO JURÍDICO}

43). Inegavelmente alguns alunos são mais afetados diante dessas emoções, porém todos são acabam em algum momento, com maior ou menor intensidade, vulneráveis a elas.

Também, como todas as pessoas, os estudantes têm um potencial para reagir emocionalmente quando estão sendo desafiados e avaliados em ambientes de grupo. "Mesmo estudantes cujos trabalhos são excelentes irão zangar-se se as práticas de avaliação e de dar notas parecerem injustas" (LOWMAN, 2004, p. 43).

Mas não só os estudantes são vulneráveis a essas emoções presente nessa arena interpessoal que é a sala de aula, os professores também estão sujeitos a elas. Os docentes também são afetados e muitos desses eventos que ocorrem podem interferir em seu prazer pela docência, pois a grande maioria dos professores almeja sucesso e realização.

A segunda dimensão trata da habilidade desenvolvida pelo professor para aumentar a motivação, o prazer e o aprendizado autônomo, mas, para isso, é necessário o professor ter consciência desses fenômenos interpessoais que ocorrem dentro na sala de aula. Em outras palavras, os professores precisam estar atentos as emoções transmitidas pelos estudantes, e serem habilidosos ao se comunicarem com eles.

Segundo Lowman, isso é feito de dois modos: o primeiro é não permitir o estimulo de ansiedade, raiva contra o professor, ou qualquer outra emoção negativa. $\mathrm{O}$ segundo é trabalhar para promoção de emoções positivas, tais como o sentimento de que o professor respeita os estudantes como indivíduos e os vê como capazes de um bom desempenho (LOWMAN, 2004 p. 44). A reunião dessas emoções é capaz de motivar os alunos a se dedicarem a disciplina, seja por almejar atingir padrões pessoais ou mesmo buscando o reconhecimento por parte do professor.

O professor Joseph Lowman sugere algumas técnicas para que o professor universitário possa estimular e manter a motivação em seus alunos: a) promover relacionamentos pessoais regularmente; b) obter feedback dos alunos regularmente; c) motivar estudantes a trabalhar por meio da liderança efetiva em sala de aula; d) mostrar especial atenção a determinados tipos de alunos; e) lidar com uma variedade de questões interpessoais (LOWMAN, 2004, p. 78). 
Segundo Blausius Silvano Debald (2003), seguindo o raciocínio da primeira dimensão de efetividade de ensino de Lowman, o principal desafio dos professores do ensino jurídico não está no domínio da matéria, mas na transmissão do conhecimento. Logo, a utilização das metodologias ativas pode preencher essa lacuna, a partir da utilização de experiências reais ou simuladas, com o fito de trazer soluções aos mais diversos problemas existentes na sociedade (BERBEL, 2011).

Para implantação de métodos ativos exige-se uma robusta formação teórica, psicológica e pedagógica a fim de que se entenda em que consiste o ato pedagógico. Jean Piaget, em sua obra Psicologia e Pedagogia, faz uma análise dos novos métodos de ensino. Alertando para a necessidade da utilização de métodos ativos mas que, em razão dos pressupostos teóricos necessários para desenvolvimento desta metodologia, acaba se buscando os métodos clássicos de ensino.

Para Celso da Cunha Bastos (2006) seriam um "processo interativo de conhecimento, análise, estudos, pesquisas e decisões individuais ou coletivas, com a finalidade de encontrar soluções para um problema”. Assim sendo, o professor seria um facilitador, permitindo que os alunos descubram e se apropriem dos conhecimentos de que precisam, possibilitando a reflexão, a pesquisa, enfim, o amadurecimento de um conhecimento jurídico independente e autônomo.

Essa metodologia ativa, segundo Correa: valoriza métodos e técnicas, como o trabalho de grupo, atividades cooperadas, estudo individual, métodos de reflexão, métodos de pesquisa (descoberta de conhecimentos), tanto na organização de experiências de aprendizagem como na seleção de métodos (CORREA, 2011, P. 54).

Devido à necessidade de se aprofundar sobre esse tema, trar-se-á algumas formas práticas do método ativo de ensino que contribuem no aprendizado do aluno. Serão trabalhadas quatro metodologias de ensino participativo, dentre tantas outras existentes e aptas a produzir efeitos pedagógicos positivos, como por exemplo, método do caso, debate, diálogo socrático, PBL - problema based method, seminário, role-play, simulação, método do caso.

Os métodos de práticas ativas de ensino jurídico escolhidos para serem abordados neste artigo foram: diálogo socrático, role- play, simulação e método do caso. 


\section{OS MÉTODOS ATIVOS DE ENSINO APLICADOS PELO PROFESSOR EXEMPLAR DE JOSEPH LOWMAN COMO INSTRUMENTOS POTENCIALIZADORES NA APRENDIZAGEM

a ) Diálogo Socrático:

Segundo José Garcez Guirardi, essa metodologia de ensino, inspirada na estratégia pedagógica utilizada pelo filósofo grego Sócrates, século V a.C., que respondia as indagações dos seus discípulos com novas perguntas, ao invés de dar-lhes explicações definitivas. Esse método traz duas consequiências imediatas, como explica Guirardi:

Uma dessas consequências - amiúde esquecida quando se discute este método de ensino - é a de que ela exigia do discípulo uma postura ativa em sua busca pelo saber, pela verdade. Implícita nas intermináveis provocações do diálogo socrático está a crença de que não é possível que alguém aprenda por nós, assim como não é possível que alguém pense por nós. A recusa em oferecer uma resposta pronta e acabada impede a atitude passiva daqueles que desejam descansar tranquilamente no magister dicet, isto é, que desejam os frutos - mas não o processo - da reflexão desenvolvida por outrem. Uma segunda consequência de peso se liga a essa postura ativa daquele que deseja conhecer. O diálogo socrático centra-se sobretudo nas formas de pensar, nas formas como o aluno estrutura suas ideias e desenvolve seus argumentos (GUIRARDI, 2012, p. 54)

b ) Role play:

Nesse método o professor irá permitir que o aluno escolha um ponto de vista, ou um papel para desempenhar para que, a partir dele, atue juridicamente no caso. $\mathrm{O}$ intuito dessa metodologia de ensino é trabalhar no aluno a capacidade de utilizar dos instrumentos juridicamente mais adequados para se chegar a uma solução. Assim como os outros métodos participativos, o role play contribui para a aprendizagem do aluno da seguinte forma:

Ao solicitar que se adote um papel, o método exige, imediatamente, que cada aluno seja capaz de avaliar o repertório de caminhos jurídicos possíveis para a promoção de um fim específico. Isso demanda não apenas um domínio conceitual sólido (sem conhecer os institutos potencialmente aplicáveis, como escolher entre eles?), mas também a capacidade de articulá-los com um fim específico - tanto jurídico como extrajurídico - que se pretende atingir. O role-play incorpora, assim, ao espaço da sala de aula, uma noção de contingência muito recorrente na prática dos escritórios: em seu cotidiano, os advogados atuam em casos concretos, em defesa dos múltiplos interesses de seus clientes. Identificar e entender tais interesses, e desenhar uma estratégia eficaz para que possam ser atendidos é parte constitutiva do que este método propõe como conhecimento jurídico (GUIRARDI, 2012, p. 59) 
c ) Simulação:

A mimese do cotidiano que informa a opção pelo role-play aparece de maneira ainda mais radical na simulação (GABBAY; SICA, 2009). Este método supõe que cada aluno, ou grupo de alunos, adote um papel, exatamente como no role-play mas, "a diferença desse, tem como foco central o modo como os alunos se portam na interação entre os diferentes atores". (GUINARDI, 2012, p. 75).

A distinção entre o role play e a simulação reside no fato de que para o role play não é necessário que os alunos assumam papeis diferentes na sala de aula, o importante neste método é atingir os objetivos pretendidos. Já a simulação pretende desenvolver no aluno as habilidades necessárias que se exige uma interação composta por diversos atores. Esse método requer que cada aluno delimite uma estratégia de ação e o provoca a adequá-la às exigências que surgirão no embate, diante das provocações dos outros atores da relação.

O método da simulação incorpora como elemento central para sua realização "o requisito de que os alunos se vejam submetidos a um elemento de imprevisibilidade [...] bem como o modo como entendem e exploram o papel institucional que lhes cabe" (GUINARDI, p. 61).

\section{d ) Método do Caso:}

Foi utilizado por Christopher Langdell no final do século XX em suas aulas no curso de Direito de Harvard e pretendia aperfeiçoar o raciocínio jurídico dos alunos quando provocados a analisarem criticamente as decisões do tribunais envolvendo casos reais. Esse método está ligada ao ensino ao ativo pois exige do aluno uma participação e reflexão ao serem instigados a analisar casos concretos de jurisprudenciais. José Guirardi aponta para a importância desse método:

Essa eleição de um objeto jurídico concreto como ponto de partida para o método do caso é um elemento central para a proposta de ensino de Langdell. Sua perspectiva didática se estrutura a partir da crença de que as decisões judiciais devam receber o mesmo tratamento metodológico que as chamadas ciências duras aplicam a seus respectivos objetos. [...] Cada decisão deve ser meticulosamente dissecada, para que se possam conhecer suas partes constitutivas e a forma como se relacionam entre si, para que possam entender sua estrutura e o modo como ela se articula 


\section{OS MÉTODOS ATIVOS DE ENSINO APLICADOS PELO PROFESSOR EXEMPLAR DE JOSEPH LOWMAN COMO INSTRUMENTOS POTENCIALIZADORES NA APRENDIZAGEM \\ DO ENSINO JURÍDICO}

para exercer determinadas funções. A partir da análise de casos específicos, da observação de constâncias e regularidades, torna-se possível estabelecer os princípios gerais que norteiam o direito. [...] Essa postura ativa é central para que o aluno apreenda tanto o repertório teórico como a forma de pensar que caracterizam o direito. Ela propicia, sobretudo, o desenvolvimento da capacidade de o aluno avaliar a qualidade de tratamento jurídico que os tribunais deram ao caso concreto: as normas aplicadas são cabíveis, consistentes com o funcionamento geral do sistema dentro do qual se inserem? As etapas e os instrumentos processuais utilizados são pertinentes e eficientes? São os mais adequados para dar conta desse caso específico? Haveria outras linhas de enquadramento capazes de produzir soluções juridicamente mais sólidas ou mais eficazes? (GUIRARDI, 2012, p.57- 58).

Os métodos participativos de ensino contribuem para formar no aluno um pensamento de reflexão e criação, oferecendo uma série de situações-problemas que precisam ser solucionadas. Permitindo ao discente correlacionar a matéria daquela disciplina com as outras e aplicar seus conhecimentos ao caso concreto, criando ou aflorando habilidades que lhe poderão ser úteis para decidir seu futuro profissional.

Ao contrário dos métodos acima propostos, a grande maioria dos métodos tradicionais atrofiam o pensamento criativo do aluno por meio dos conteúdos dogmáticos e excesso de exposição e verbalização unilaterais. Já as estratégias adotadas pelo método ativo quando inseridas na metodologia clássica permitem a participação dos alunos por meio de debates, pesquisas, discussões, atividades práticas, dente tantas outras.

O presente trabalho defende a aplicação do método ativo no ensino jurídico, aplicado pelo estereotipo do professor exemplar, proposto por Lowman, como forma de incentivar a participação do aluno em sala de aula, e evitar eventuais frustrações dos professores que não encontram entusiasmo em suas turmas. Nesse sentindo, percebe-se que ensinar não requer apenas a acumulo de conhecimentos técnicos, mas também, o domínio de técnicas de ensino, capacitação pedagógica, bem como a utilização de métodos que proporcionam uma efetiva aprendizagem. 


\section{CONCLUSÕES}

O ensino jurídico no Brasil deve buscar novos mecanismos que facilite a aprendizagem do aluno, com técnicas pedagógicas e o modelo de ensino proposto por Lowman encontra-se um caminho para tal fim. Isso porque métodos de ensino que possuem como protagonista a figura do professor, sem que se abra um espaço um relacionamento interpessoal com os alunos, precisam ser repensados pelos docentes e Universidades. É necessário abrir espaço para que na sala de aula o aluno sinta-se a vontade para refletir e participar da disciplina.

Os problemas atinentes ao modelo tradicional de ensino são minimizados ou, até mesmo deixam de existir, quando o professor abre para a possibilidade de interação com os alunos, possibilitando-os a refletir sobre o assunto. Ao utilizar de outras técnicas ou métodos de ensino, os docentes estimulam a reflexão dos seus alunos, abrem margem para um pensar autônomo e proporcionam uma maior eficiência no processo de aprendizagem.

Nessa perspectiva, o modelo de professor exemplar sugerido por Joseph Lowman, através das duas dimensões, estímulo intelectual e relacionamentos interpessoais, combinado a métodos ativos de ensino, proporcionará uma satisfação e motivação tanto para os alunos como para os professores. 


\section{REFERÊNCIAS}

BASTOS, C. C. Metodologias Ativas. Disponível em: http://educacaomedicina.blogspot.com.br/2006/02/metodologias-ativas.html.

BERBEL, N. A. N. As metodologias ativas e a promoção da autonomia de estudantes. Ciências Sociais e Humanas, Londrina, v. 32, n. 1, p. 25-40, jan./jun. 2011.

COLAÇO, Thais. Ensino do Direito e Capacitação Docente. In COLAÇO, Thais (Coord). Aprendendo a ensinar Direito. Florianópolis: OAB/SC, 2006.

CORREA, Adriana K. et al. Metodologia problematizadora e suas implicações para a atuação docente: relato de experiência. Educação em Revista, Belo Horizonte, v. 27, n. 3, p. 61-78, dez. 2011.

FREIRE, Paulo. Pedagogia do oprimido. Rio de Janeiro: Paz e Terra, 2005.

GHIRARDI, José Garcez. (org.). Métodos de ensino em direito: conceitos para um debate. São Paulo: Saraiva, 2009.

. (coord.). Cadernos DIREITO GV: avaliação e métodos de ensino em direito, vol. 7, n. 5, set. 2010a.

. O instante do encontro: questões fundamentais para o ensino jurídico.

São Paulo: Fundação Getulio Vargas, 2012.

GIL, Antonio Carlos. Metodologia do ensino superior. 4ªed. São Paulo: 2009.

LOWMAN, Joseph. Dominando as técnicas de ensino. São Paulo: Atlas, 2004.

MELO FILHO, Álvaro. Metodologia do ensino jurídico. Fortaleza: Imprensa universitária da Universidade Federal do Ceará, 1977.

PESSOA, Flávia Moreira Guimarães (org.). Reflexões sobre a docência jurídica. Série Estudos de Metodologia. Volume 1. Aracaju: Evocati, 2013.

PIACENTINI, Dulce de Queiroz. Vygotsky, Freire e Morin e a Educação para os Direitos Humanos. In COLAÇO, Thais (Coord). Aprendendo a ensinar Direito. Florianópolis: OAB/SC, 2006.

PIAGET, Jean. Psicologia e Pedagogia. Rio de Janeiro: Forense 1980.

PIRES, Patrícia da Silva. A Discussão enquanto Técnica de Ensino do Direito que efetiva o Construtivismo no Processo Ensino-Aprendizagem. In COLAÇO, Thais (Coord). Aprendendo a ensinar Direito. Florianópolis: OAB/SC, 2006

SOUZA, Paulo Nathanael Pereira de. LDB e educação superior: estrutura e funcionamento. 2. ed. rev e ampl., São Paulo: Pioneira Thomson Learning, 2001. 